\title{
How to Make Grounded the Preferred Approach to Psychological Research? a Systematic Review
}

\author{
Ika Febrian Kristiana \\ Doctoral Psychology Program, Universitas Airlangga \\ Faculty of Psychology, Universitas Diponegoro \\ lka.f.kristiana@gmail.com \\ Suryanto \\ Doctoral Psychology Program, Universitas Airlangga \\ suryanto.psikologi@unair.ac.id \\ Wiwin Hendriani \\ Doctoral Psychology Program, Universitas Airlangga \\ wiwin.hendriani@psikologi.unair.ac.id
}

\begin{abstract}
Grounded theory has proven to be a very popular methodological choice for researchers in areas such as education, health, and social since 1960. This review aims to identify and describe the use of grounded theory in the field of psychology. The online database was used as a source including psycINFO, ScienceDirect, and Proquest. There are $(\mathrm{N}=18)$ articles resolved through the screening process by setting exclusion or inclusion criteria. The results of the review on the application of grounded theory in psychology research can be grouped in several points including how to write the title of research, research objectives, to step-by-step grounded theory implementation, technically ranging from researcher attitude, role, and treatment to literature, data collection, its findings. Two grounded theory versions are identified (i.e, classic grounded theory and constructivist) and described in detail the technical applications that can be chosen by the researcher by considering the differences (strengths and weaknesses) between the two. Understanding and disciplined and consistent application of grounded theory will help contribute either in the building, developing, or filling the theoretical gaps that exist.
\end{abstract}

Keywords: classic grounded theory, constructivist grounded theory, psychology

Received 18 April 2019/Accepted 8 July 2019 @JEHCP All rights reserved

\section{Introduction}

Research with qualitative methods in the field of psychology began to emerge in the 20th century (Rennie, Watson, \& Monteiro, 2002). This condition is inseparable from the long history of the birth of psychology. Psychology appears as one of the sciences, but centuries of psychology are nothing more than reflecting philosophical prejudices and conclusions. In reality, psychic phenomena about the soul that became the study at the beginning of the emergence of Psychology was considered a metaphysical phenomenon that was difficult to obtain data. Shifting views occur towards psychic studies in Psychology towards the conscious phenomenon as a manifestation of mental activity. Conscious natural phenomena 
are considered more likely to be extracted empirically. Metaphysical and empirical trends do not necessarily make them exclusive, but each has explanatory power to a certain extent (Klemm, 2017). However, the way of looking at the reality or the essence of psychology that is rooted in the definition of psychology as a science in philosophical studies referred to as ontology will influence methodological problems in scientific psychology activities (Leal, 2000).

The ontological view of the reality or essence of psychology as pluralistic is a way of looking at the object of study in an interpretative approach or often referred to by methodological experts as qualitative research (Hanurawan, 2012). The qualitative approach is an inquiry method in social and health disciplines that emphasizes verbal text meaning. Basically, this method is more subjective, exploratory, descriptive, and more interpretive than the positivist approach (Denzin \& Lincoln, 1994). The birth of qualitative research is also a psychological effort that develops as a science finding answers to the crisis of confidence about its methodology. Dissatisfaction with scientific activities that only imitate or imitate, focuses on developing complex research and analysis technologies, but ignores the main tasks in science, namely thought and discovery (Bakan, 1967 in, Rennie, Phillips, \& Quartaro, 1988).

The legitimacy of qualitative research by academics does not apply to all approaches in qualitative. In a review of qualitative research, there are several approaches in qualitative that are recognized as an inquiry method in psychology after a study of an international research database (e.g, psycINFO). Some approaches that gain legitimacy include grounded theory, discourse analysis, and phenomenology (Rennie et al, 2002). In 1967, Barney Glaser and Anselm Strauss laid the foundation for the discovery of theory from empirical data which later became the beginning of the development of grounded studies. Historically, grounded theory has represented epistemological resolution that is different from the qualitative approach that developed earlier (eg symbolic interactionism) and solutions to broader problems about skepticism about the status of qualitative-based knowledge in social science. In the decades after 1967, grounded theory has been widely used in studies because it is considered to offer rigorous analytical methods in fields such as education and health (Harry, Sturges, \& Klinger, 2005; Chiovitti \& Piran, 2002; Alvesson \& Sko“ldberg, 2000). 
Grounded theory is one approach in qualitative research that aims to develop the theory by finding theories based on empirical data, rather than constructing theories deductively logically (Parse 200I; Charmaz 2000; Glaser, 1999; Strauss \& Corbin, 1990). The grounded method seeks to investigate something from individuals who interact and or experience the process of the phenomenon being studied. To conduct research with this method data from individuals involved in the process of research phenomena must be obtained carefully and deeply through efforts to extract natural data, namely interviews (Morse, 200I). In addition to interviews, researchers must also understand the field conditions that helped shape the phenomenon of research by making repeated visits to the field and observation. Next, researchers will build and relate information categories, write theoretical propositions, and then visualize the theory built.

In its development, there are several versions of the grounded theory approach, namely classical grounded theory (Glaser, 1998; Glaser, 1992; Glaser \& Strauss, 1967) and constructivist grounded theory (Strauss \& Corbin, 1994; Charmaz, 2000). Researchers must have strong ontological and epistemological beliefs in determining the choice of using a particular version of grounded theory (MacDonald \& Schreiber, 200I; Wuest \& MerrittGray, 200I) also need to pay attention to some of the criticisms given to this method. The second difference in the grounded theory version will be discussed in the review results. But basically, when researchers have decided to be bound by grounded studies, a number of characteristics must be met, including: sensitivity theory, theoretical sampling, how to treat and use literature, rigorous data collection techniques, consistent data analysis techniques, and how to verify meaningful ((McCann \& Clark, 2003). This study aims to identify and describe the use of grounded theory as a research approach in psychology. This study will also describe how important or grounded theory contributions to psychology were when applied in research.

\section{Method}

Literature search

Online literature searches were conducted using the main databases which contained many articles in psychology, including PsycINFO, ScienceDirect, and Proquest. The search time is carried out for 2 weeks in the range of 12-26 May 2018. The period of publication of the article is limited to the last 10 years in the range of 2008-2018. Keywords used in the 
literature search are: "grounded theory" AND "research" AND "psychology". Based on the literature search, a total of 1475 research articles were obtained.

The screening was conducted on 1475 articles found by setting inclusion and exclusion criteria. The inclusion criteria set include I). research on phenomena or topics in psychology; and 2). using the grounded theory method. The exclusion criteria set by the researcher include I). English articles; 2). full-text can be downloaded, and 3). Research article or review report (peer reviewed article). Screening results through inclusion and exclusion criteria then continued with the selection of abstract contents obtained 18 articles which will be analyzed further consisting of 16 published research articles in journals and 2 published online dissertation articles.

\section{Analysis}

This study aims to identify and describe the application of grounded theory in research in psychology. The review was carried out systematically on $(N=18)$ articles that had gone through a screening and selection process by identifying: the author and year of publication, how to write the title of the research with grounded theory, how to state the research objectives (and or research questions) with grounded theory, and steps - the steps of applying the grounded theory design are used.

\section{Result}

Based on a literature review, the application of a grounded approach to research in the field of Psychology is elaborated on the following points.

Formulate the title

Some examples of sentence formulations in psychology research titles that use grounded theory are presented in table I below. 
Table I

Formulations on the title of research in psychology with the grounded theory approach

Author (name \& year)

Massey, Meyer, \& Naylor (2013)

McCreaddle \& Wiggins (2009)

McPherson, Hiske, \& Alderson (2016)

Meyer, Frank, Muntwyler, Fleming, Pehlke-Milde (2017)

Rabahi, Yusof, \& Awang (2015)

Portelli \& Eldred (2017)

Ginanjar (2007)

Villanueva (2014)

Fletcher \& Sarkar (2012)

Cummings (2018)

Izvercian, Potra, Ivascu (2016)

Renolen, Hoye, Hjalmhult, Danbolt, Kirkevold (2018).

Takaoka, Mizoguchi, Wada, Nakazato, Shiraishi, Ando, Masaomi, \& Shimiz (2016)

Veladat \& Navehebrahim (201I)

Khankeh, Hosseini, Rezaie, Shakeri, Schwebel (2015)

Lawlor \& Kirakowski (2013)

Lovell (2016)
The research's title

Towards a grounded self-regulation theory in mixed martial arts Reconcile good patient persona with problems and humor that are not problematic: a grounded theory

Distress in working on dementia wards (Treats to loving care): A grounded theory study

Decision-making in giving birth at home: A grounded theory study

Lead learning: A grounded theory perspective on "Orang Asli) A grounded theory of attitudes towards online psychological interventions in pain management in patients with chronic pain The process of developing a quality of life for individuals living with new families (after adaptation): a grounded theory

Understanding the autistic spectrum holistically

Building professional relationship: a study with the classical grounded theory on teacher experience

A grounded theory of psychological resilience to Olympic championship

Transformation in parenting practices for children who have experienced interpersonal trauma: a grounded theory of parental responses

Job satisfaction variables: a grounded theory approach

"Stay on track", Hospital nurses who struggle to maintain the workflow while trying to integrate evidence-based practice into their daily work: A study of grounded theory

How parents suspected of maltreatment change cognition and behavior: A model of child protection and outreach processes produced through grounded theory

Designing model for managing student talent in elementary schools: A qualitative study based on grounded theory

A model to explain suicide by self-burning among Iranian women: A grounded theory study

When lies are the truth: Grounded theory analysis from online groups supporting factitious disorder

How parents process child health and nutrition information: A grounded theory model

There is no specific standard in formulating research titles using the grounded theory method. Some examples of the titles above illustrate that as the title in qualitative research with various approaches shows the existence of language arts (hermeneutics) so that it looks interesting but still represents the phenomenon to be studied. 
Research purposes

Some examples of sentence formulations to state the purpose of research in grounded theory research are described in table 2 below.

Table 2

State the research objectives with the Grounded theory

\begin{tabular}{cl}
\hline No & \multicolumn{1}{c}{ State the purpose of the research } \\
\hline I. To find out how the process of occurrence of phenomenon is examined \\
2. To find out reasons from the perspective of individuals who experience or are directly involved \\
with the phenomenon under study so that a theoretical model can be prepared to explain \\
phenomenon \\
3. To explore and explain a phenomenon more deeply and comprehensively \\
4. To develop a theory related to a comprehensive process explanation of phenomenon \\
5. To produce theories based on general patterns of behavior found \\
6. To develop a conceptual model to explain the relationships between the main categories \\
7. To fill in the gaps in the literature that have not been explained through positivistic research \\
8. Dethod \\
9. To better understand the psychological factors involved in the occurrence of phenomenon \\
10. Investigate complex and dynamic phenomena in certain contexts
\end{tabular}

In the examples writing down the research objectives with the grounded method above, some typical words are used, among others: describing or developing a process model, developing a theory, developing a conceptual model to explain relationships, exploring phenomena naturally based on context, understanding and describing the psychological dynamics behind a phenomenon.

Steps for implementing the grounded theory

The application of technical grounded theory as a research method is carried out in different styles or versions. Based on a review of 18 psychological research articles using the grounded theory method, there are 2 versions of the grounded theory, i.e: classic grounded theory and constructivist grounded theory. The following is an explanation of each version along with the stages / technical applications in the study: 
Classic grounded theory (Glaser \& Strauss, 1967)

According to Glaser \& Straus, a classic grounded theory is not a linear process. The stages in classic grounded theory explained by Glaser \& Strauss include I). data collection; 2). theoretical sampling; 3). constant comparative analysis; 4). memoing (ensuring that theory is based on data); 5). Theoretical Outline; 6). Integration of Literature; 7). Writing: Generation of Theory. The stages above will ultimately lead to efforts to sort the theory and the next generation of theory. Throughout this classic grounded process, it is very important to emphasize the effort to minimize the researchers' preconceptions so that the theories obtained are truly accurate and reflect the data. Classic grounded theory leads to efforts to increase the capacity of social scientists to produce theories that are relevant to the subject/ participant. In classic grounded theory studies, researchers do not begin their research with hypotheses or research questions but begin with general research topics.

\section{Data collection}

The theoretical discovery process in classical grounded theory is not tainted by logical elaboration because each concept must get its way into theory through an emergent fit so as to avoid what is called "force" data or matching data and theory (Glaser, 1978). Therefore, a literature review is carried out after the data is collected. If the initial data comes from the interview, the grand tour question based on the research topic, in general, should be used as an initial reference for the interview. Research on common topics will guide researchers to know where to start collecting data.

\section{Theoretical sampling}

Theoretical sampling is the process of collecting data to produce a theory, where the researcher will collect, encode, and analyze data then decide what and where data is found to generate or develop theories. In classic grounded theory most of the data is collected through intensive interviews with open questions, but other sources of data collection, such as observation and archival data can be used.

\section{Constant comparative analysis (coding)}

After the first interview, the researcher began the process of analyzing the data by immediately encoding the results of the interview. Glaser (1992) defines coding as, conceptualizing data with a constant comparison of incidents with incidents, and incidents with concepts to bring up more categories and properties. When the researcher does the 
coding, the researcher can determine who to do the next interview or where to go to retrieve the next data source. At the same time can give an idea of what to look for in the next interview.

There are two types of coding in analyzing data, namely, substantive and theoretical coding (Glaser, 1978). In the substantive coding, the researcher asked three general questions about data, namely: I). What is learned from the data; 2 ). The incident shows what category ?; 3). What really happens in the data? There are two types of substantive coding, namely: open coding and selective coding. Open coding is done by coding data in every possible way to find the core variable. Whereas selective coding is done by limiting coding only to variables related to core variables and important in parsimony theory.

\section{Memoing}

The entire research process is written in a memo by the researcher where the memo is then a developing body of theory (Glaser, 1978). A memo is a theoretical jump containing ideas about what has been encoded and the relationships that researchers find when coding (Glaser, 1978). Researchers must write these memos because they can be a source of ideas and prevent forgetfulness. When researchers write memos, researchers must think theoretically and not have to care about caring about the correct use of grammar, spelling, and so on. Memoing starts when you first encode data and continues through reading memos or literature, sorting and writing papers or monographs to the end. Theoretical shorting is an important step in the classic grounded theory process and cannot be passed. Through sorting, researchers place concepts and memos organized into a theoretical outline, using theoretical codes that allow evolution in the design of theory (Glaser, 1978). This step is carried out by bringing data and memos together in the preparation process for writing. The process of writing the theory itself will always involve theoretical sorting of the memos. If a researcher removes a part of this process, the resulting theory will not have all aspects of a good theory but is only flat and without dimensions.

\section{Theoretical Outline}

Next, researchers write a theoretical outline. Writing a theoretical outline and sorting memos by cutting and pasting memos leads to the creation of an initial outline of the theory while showing the relationship of each concept to the core variables. In a theoretical outline, researchers organize data into theory based on the core of the variable taking into account 
properties and differences in core variables. The theoretical outline helps researchers to organize theory by showing the relationship of each property to each other and with theory.

Integration of Literature

In classical grounded theory, Glaser and Strauss (1967) explained that it is important not to start research with literature reviews so that researchers remain free and avoid theoretical bias, unrelated opinions, unrelated concepts, or any preconceptions. When researchers feel confident in theory, they integrate relevant literature and analyze it as part of the data. A literature search in the substantive field can be completed and woven into theory during the sorting and writing stages. The literature review at this point makes the theory clearer because it takes theory into the substantive territory (Glaser, 1998).

\section{Writing: Theory of Generation}

The final step is writing theory. This process involves synthesizing sorted memos and placing them in written forms where core variables will explain behavior (Glaser, 1978). Theory writing focuses on the core variables in relation to the dimensions, categories, and properties found during the analysis process. Researchers can make several revisions before completing the theory. Classic grounded theory research is a very thorough work, but if practiced appropriately, researchers can find a theory that remains true and grounded in data.

\section{Constructivist grounded theory}

Constructivist grounded theory can be traced to the work of Strauss (1987) and Strauss and Corbin (1990, 1994, 1998) which are supported by their relativism position and show in their belief that researchers build theory as a result of their interpretation of data. Strauss and Corbin's focus on technical analysis in a grounded process confirms their constructivist intentions (Mills, Bonner \& Francis, 2006). The next researcher who first introduced his work explicitly as a theory based on constructivism is Charmaz (2000). He stressed the importance of researchers to be close to the data through efforts to keep their words intact in the analysis process. The key to doing this is to write creatively as a form of expression that has the potential to communicate how participants build their world. 
There are several important differences between the constructivist grounded theory approach and the traditional / classical theory approach. The following is an explanation of these differences.

\section{Theoretical sensitivity}

Theoretical sensitivity is a multidimensional concept of insight and the ability of researchers to align their theoretical insights with nuances and data. This concept also includes the ability of researchers to reconstruct the meaning of the data generated and separate those concerned and those that are not (Strauss \& Corbin, 1990). In this grounded version there appears to be a dependency on researchers in terms of data immersion that appears to increase their theoretical sensitivity. According to Strauss and Corbin (1998), that theory is an attempt to build a "concept" of schematic explanation of data by integrating various concepts through the relationship of systematic statements that authenticate authenticity. That theory itself is an interpretation from the researcher's perspective (Strauss \& Corbin, 1994).

\section{Treatment of literature}

Classical grounded theory does not advise researchers to review any of the literature in the substantive area under study (Glaser, 1992) because it will contaminate or inhibit the researcher. Data is placed as an entity separate from participants and researchers. In fact, constructivist ground theory pays attention to the benefits of information obtained from proactive involvement with the literature at the beginning of the research process (Strauss \& Corbin, 1998). Researchers as much as possible establish literature throughout the grounded process as "other voices" that contribute to grounded researchers' theoretical sensitivity. Literature can be used by researchers to examine examples of similar phenomena to stimulate the thinking of researchers in understanding the nature or dimensions of data.

"Non-technical" literature can include internal reports as potential data sources that provide information about the context of participant experiences such as organizations /workplaces (Strauss \& Corbin, 1998). These works of literature then contribute to the analysis of additional data relating to meso and macro conditions that might affect participants (Corbin, 1998). 
Coding and diagrams

Complex coding methods are used by Strauss and Corbin (1998) as a strategy for examining structures and processes. It also shows that they pay more attention to the interaction of social groups and the participants' "world".

Simplifying the paradigm framework through axial coding was introduced by Strauss and Corbin in other writings. Axial coding is a coding step whose process is done by asking questions about the conditions, actions / interactions, and consequences of categories, which results in the relationship between conceptualization of ideas based on data. Strauss and Corbin also provide guidance for axial coding. In the guide mentioned that axial coding can be done by provoking thoughts about the relationship between categories and properties and dimensions. This effort was made to fulfill the requirements to use the paradigm. However, this coding should not be used rigidly which can prevent researchers from trying to capture the dynamics of events and the complexity of their relationships.

In addition to axial coding, another "tool" that can be used to broaden the area of researcher analysis by basing on expanding the analytical work dimensions of constructivist researchers based on the conditional / consequential matrix. Strauss and Corbin (1998) describe a conditional matrix as an analytical tool to help track the relationship between the conditions/consequences and subsequent actions/interactions and to track the connectivity pathway. The researcher uses the matrix to find interactions that appear repeatedly in the data and then trace the relationships or micro and macro conditions that might affect the interaction (Corbin \& Strauss, 1996). This enables the reconstruction of original data by the researcher, making the broad context clear. The diagram is the center of the coding process used extensively by Strauss and Corbin. Logic diagrams such as flowcharts can be used in the initial coding process. In the higher analysis process, the researchers used conditional/ consequential matrices and integrative diagrams in describing the complexity of interactions between various conditions (Strauss \& Corbin, 1990, 1998; Charmaz, 2000).

\section{Identify core categories}

Core categories are the main focus of the grounded approach. The core category is the process of integrating all aspects of theory. Process development in core categories is carried out to recognize the role of researchers as authors of the theoretical reconstruction that occurs during selective coding processes (Strauss and Corbin, 1998). In Particular, some 
efforts are needed to reach this stage, including: exploring the centrality of the story, interpreting the analysis in the narrative, and developing the final core categories. The final result or conceptualization of this stage is the story line. Therefore, according to Strauss \& Corbin (1990) conceptual labels must match and represent stories or data. In this process, stories from researchers who reconstruct participants can be recognized (Strauss \& Corbin, 1994).

\section{Discussion}

However, the questions raised in qualitative research provide a challenge to prove that the choice of using a grounded theory approach in research is an appropriate choice to answer questions and problems. Included in the choice of using grounded theory as a method of qualitative approaches there are several challenges faced by grounded theory researchers. The first challenge, researchers are expected to have theoretical ideas and conjectures as an effort to increase theoretical sensitivity but still maintain "distance" with data. Second, researchers must realize that a grounded theory approach is a systemic approach and must go through steps for data analysis. Third, researchers will often have difficulty determining when information or data is considered detailed and sufficient. Fourth, researchers must really understand that the results of research with grounded are finding a theory with specific components.

The researcher is expected to have a strong understanding and consideration in choosing a version of the grounded theory that will be used and consistent in following every philosophical basis and steps in it. Researchers who understand and discipline the grounded approach will be able to help develop or build a theory that is able to fill in the theoretical gaps that exist and or explain behavior so far in their research area (Glaser, 1978).

\section{Theoretical Implication}

The findings of this study include information about the history, types, and implications of different types of grounded theory in the steps of the study. It aims to build a theory based on interpretation of data patterns. In the Psychology study, building theory through grounded theory is carried out on the interpretation of behavioral patterns. In the beginning, the implementation of grounded theory shows significant difficulties. The difficulty faced when using this method is how to explain to the reader about the reality based on this approach (Allan, 2003) especially in the field of Psychology. However, along with the 
development of studies in the field of Psychology, the grounded theory which is born from the perspective of social constructivism, is very relevant to the development of a humanistic psychology study and related to the cultural context (Gravetter \& Forzano, 2006).

\section{Limitations and Direction for Future Research}

This study uses three online databases with the consideration that the database contains most of the publications one of them in the field of psychology. There are other databases that should be considered as online sources to expand the picture related to the topic of studies from social science for example SSCl. Limiting keywords in the search by adding the word "review" also needs to be considered to ensure that the same review has never been done.

\section{Conclusion}

Grounded theory is an approach that makes an important contribution to its application to psychological research. A comprehensive understanding of this approach ranging from philosophical history, types, to the applicative technical will help researchers carry out grounded research to achieve the goal of constructing theories to explain behavior as objects of psychological study

\section{Acknowledgement}

The researcher would like to thank the education funding agency (LPDP) for providing financial assistance during the study. Thanks are also given to the Airlangga University psychology doctoral program for all the support given.

\section{References}

Allan, G. (2003). A critique of using grounded theory as a research method. Electronic Journal of Business Research Methods, 2, I, I-I0. http://www.ejbrm.com.

Alvesson, M. \& Sko“ldberg, K. (2000) Reflexive methodology: New vistas for qualitative research. London: Sage.

Charmaz, K. (2000). Grounded theory: objectivist and constructivist methods. In Handbook of Qualitative Research, 2nd edn (Denzin N.K. and Lincoln Y.S., eds), Pp. 509-536. London: Sage Publications, Inc. 
Chiovitti, D., F, \& Piran, N (2002). Methodological issues in nursing research: Rigour and grounded theory research. Journal of Advanced Nursing, 44(4), 427-435.

Clarke, A. (2005). Situational analysis: Grounded theory after the postmodern turn. Thousand Oaks, CA: Sage.

Corbin, J. (1998). Alternative interpretations: Valid or not? Theory \& Psychology, 8(I), I2I128.

Corbin, J., \& Strauss, A. (1996). Analytic ordering for theoretical purposes. Qualitative Inquiry, 2(2), $139-150$.

Cummings, J., A. (2018). Transformational change in parenting practices after child interpersonal trauma: A grounded theory examination of parental response. Child Abuse \& Neglect, 76, II7-128. doi: 10.1016/j.chiabu.2017.10.005.

Denzin, N. K., \& Lincoln, Y. S., ( 1994). Handbook of qualitative research. London: Sage.

Fletcher, D. \& Sarkar, M. (2012). A grounded theory of psychological resilience in Olympic champions. Psychology of Sport and Exercise, 13, 669-678. doi:I0.1016/j.psychsport.2012.04.007.

Ginanjar, A., S. (2007). Memahami spectrum autistic secara holistik. Makara sosial humaniora, II (2), 87-89.

Glaser, B. G. \& Strauss, A. L. (1967). The discovery of grounded theory: strategies for qualitative research. New York, Aldine.

Glaser, B. G. (1992). Basics of grounded theory analysis. Mill Valley, CA: Sociology Press.

Glaser, B. G. (1998). Doing grounded theory: Issues and discussions. Mill Valley, CA: Sociology Press.

Glaser B.G. (1999). The future of grounded theory. Qualitative Health Research, 9, 836-845.

Glaser, B. G., \& Strauss, A.L. (1967). The discovery of grounded theory. Chicago, IL: Aldine.

Gravetter, F. J. \& Forzano, L. B. (2006). Research methods for the behavioral sciences. Belmont, CA: Thomas Wadsworth.

Hanurawan, F. (20I2). Filsafat ilmu psikologi. Malang: Universitas Negeri Malang.

Harry, B., Sturges, K. M. \& Klinger, J. K. (2005) Mapping the process: an exemplar of process and challenge in grounded theory analysis, Educational Researcher, 34(2), 3-13.

Izvercian, M., Potra, S., Ivascu, L. (2016). Job Satisfaction Variables: A Grounded Theory Approach. Procedia - Social and Behavioral Sciences, 221, 86 - 94.

Khankeh, H., R., Hosseini, S., A., Rezaie, L., Shakeri, Schwebel, D., C. (20I5). A model to explain suicide by self-immolation among Iranian women: A grounded theory study. Article in press. b u r $n$ s. http://dx.doi.org/10.1016/j.burns.2015.03.015. 
Klemm, O. (2007). A history of psychology, translated by Supriyanto Abdullah. Yogyakarta: Indoliterasi.

Lawlor, A., \& Kirakowski, J. (20I3). When the lie is the truth: Grounded theory analysis of an online support group for the factitious disorder. An article in press. Psychiatry Research http://dx.doi.org/I0.1016/j.psychres.2014.03.034.

Leal, L. (2000). Essentials of psychology. Piscataway, New Jersey: Research \& Education.

Lovell, J., L. (2016). How parents process child health and nutrition information: A grounded theory model. Appetite, 97, I38-I45. http://dx.doi.org/I0.10 I6/j.appet.20I5.I I.024

MacDonald, M., \& Schreiber, R. (200I). Constructing and deconstructing: Grounded theory in a postmodern world. In R. Schreiber \& P. N. Stern (Eds.), Using grounded theory in nursing (pp. 35-54). New York: Springer.

Massey, W., V., Meyer, B., B. \& Naylor, A., H. (2013). Toward a grounded theory of selfregulation in mixed martial arts. Psychology of Sport and Exercise, 14, 12-20. doi: 10.1016/j.psychsport.2012.06.008.

McCann, T., \& Clark, E. (2003). Grounded theory in nursing research: Part 3-Application. Nurse Researcher, I I(2), 29-39.

McCreaddie, M. \& Wiggins, S. (2009). Reconciling the good patient persona with problematic and non-problematic humour: A grounded theory. International Journal of Nursing Studies, 46, 1079-1091. doi:10.1016/j.ijnurstu.2009.01.008.

McPherson, S., Hiske, S., \& Alderson, Z. (2016). Distress in working on dementia wards - A threat to compassionate care: A grounded theory study. International Journal of Nursing Studies, 53, 95-104. doi 10.1016/j.ijnurstu.2015.08.013.

Meyer, Y., Frank, F., Muntwyler, F., S., Fleming, V., Pehlke-Milde, J. (2017). Decision-making in Swiss home-like childbirth: A grounded theory study, Women Birth (article in press, 2017), doi: 10.1016/j.wombi.2017.05.004.

Mills, J., Bonner, A., Francis, K. (2006). The Development of Constructivist Grounded Theory. International journal of qualitative method, 2006, 5(I).

Morse, J. (200I). Situating grounded theory within qualitative inquiry. In R. Schreiber \& P. N. Stern (Eds.), Using grounded theory in nursing (pp. I-16). New York: Springer.

Parse R.,R. (200I). Qualitative inquiry: The path of sciencing. Jones \& Barlett Publishers, Toronto.

Portelli P. \& Eldred C. (20I7). A grounded theory of attitudes towards online psychological pain management interventions in chronic pain patients, Computers in Human Behavior (2017), doi: 10.1016/j.chb.2017.07.034.

Rabahi, M., Yusof, H., \& Awang, M. (2015), Leading learning: A grounded theory perspective of orang asli parental involvement and engagement, 2nd Global Conference on Business and Social Science-20I5, GCBSS-20I5, 17-18 September 2015, Bali, Indonesia. Procedia - Social and Behavioral Sciences, 21 I, 94 - 103. 
Renolen, A., Hoye, S., Hjalmhult, E., Danbolt, L., J., Kirkevold, M. (20I8). "Keeping on track"- Hospital nurses' struggles with maintaining workflow while seeking to integrate evidence-based practice into their daily work: A grounded theory study. International Journal of Nursing Studies, 77, 179-188. doi: 10.1016/j.ijnurstu.2017.09.006.

Rennie, D., L., Phillips, J., R., \& Quartaro, G., K. (1988). Grounded theory: A promising approach to conceptualization in psychology. Canadian Psychology, 29, 2.

Rennie, D., L., Watson, K., D., Monteiro, A., M. (2002). The rise of qualitative research in psychology. Canadian Psychology, 43, 3.

Senese, M. J. (2012). The process of developing a perceived quality of life for those living together with their immediate family: A grounded theory, an online dissertation. Ann Arbor, USA: Proquest.

Strauss, A. (1987). Qualitative analysis for social scientists. Cambridge, UK: Cambridge University Press.

Strauss A.L. \& Corbin J. (1990). Basics of Qualitative Research: Grounded Theory Procedures and Techniques. Newbury Park: Sage Publications.

Strauss, A., \& Corbin, J. (1994). Grounded theory methodology: An overview. In N. Denzin \& Y. Lincoln (Eds.), Handbook of qualitative research (pp. 273-285). Thousand Oaks, CA: Sage.

Strauss, A., \& Corbin, J. (1998). Basics of qualitative research: Techniques and procedures for developing grounded theory (2nd ed.). Thousand Oaks, CA: Sage.

Takaoka, K., Mizoguchi, F., Wada, I., Nakazato, M., Shiraishi, T., Ando, S., Masaomi, I., \& Shimiz, E. (20I6). How parents suspected of child maltreatment change their cognition and behavior: A process model of outreach and child protection, generated via grounded theory. Children and Youth Services Review, 7I, 257-265. doi: 10.1016/j.childyouth.2016.11.019.

Veladat, F., Navehebrahim, A. (20I I). Designing a model for managing talents of students in elementary school: A qualitative study based on grounded theory. International Conference on Education and Educational Psychology (ICEEPSY 20II). Procedia Social and Behavioral Sciences, 29, 1052 - 1060.

Villanueva, C., M., A (20I4). Building professional relationship: A classic grounded theory study of experiences of teachers, an online dissertation. Ann Arbor, USA: Proquest

Wuest, J., \& Merritt-Gray, M. (200I). Feminist grounded theory revisited: Practical issues and new understandings. In R. Schreiber \& P. N. Stern (Eds.), Using grounded theory in nursing (pp. 159-176). New York: Springer. 